\title{
Overseeing Study Abroad Research: Challenges, Responsibilities, and the Institutional Review Board
}

\author{
Ber $\mathbf{n h a r d}$ Streitwieser \\ Nortbwestern University
}

\author{
Neal Sobania \\ Pacific Lutheran University
}

\section{Introduction}

This introduction to the third special issue on undergraduate research raises the question of oversight of undergraduate research during study abroad, the responsibilities of sending and receiving institutions for training and preparing students, and what role campus or program Institutional Review Boards (IRBs) should play in that process.

Over the past several decades, universities have increasingly worked to create ways to involve undergraduates in research that has traditionally been conducted by faculty and graduate students (Gonzalez, 2001; Bauer and Bennett, 2003; Lopatto, 2004). The landmark 1998 Boyer Commission report, Reinventing Undergraduate Education: A Blueprint for America's Research Universities, proposed that universities find pathways for undergraduates to engage in independent and collaborative research activities that help bridge graduate and undergraduate research (Boyer Commission, 1998). Across the country, research has been steadily growing as a standard component of the undergraduate university curriculum (Fortenberry, 1998; Katkin, 2003). Building on this, universities have gradually begun seeing the added value of students gaining genuine research experiences as they venture abroad (Hopkins, 1999). Greater numbers of students today are being given the opportunity by their institutional study abroad office, being required by their program providers, or simply articulating a personal interest in, conducting research abroad.

However, a description of the scope of undergraduate research during study abroad and what place it has in the wider spectrum of academic inquiry seems to be missing. Some academics struggle to differentiate what they consider actual or 'real' research from student research. Kallgren \& Tauber (1996) reported that some academics still regard undergraduate research as not "real" research when compared with graduate or professional level research (p. 2000). 
As education abroad professionals and academics actively involved in research, writing and publishing, we fully support undergraduate research as part of study abroad if it is undertaken appropriately. For the purposes of this article, undergraduate research is defined as inquiry that is conducted independently by the student, involves several weeks of intensive and self-driven data collection, analysis, and writing, and in the end represents individual student achievement. Imagine the following four scenarios, all of which are based on actual student research proposals.

1. You are a study abroad advisor accustomed to helping students find a program that will meet their interests and satisfy their academic requirements. A student comes to you determined to conduct a research study during her fall semester in Scotland. Her intention is to explore college aged drinking and related sexual experiences. The student, majoring in history, has never taken a research methods course, does not know what "human subjects protection" is, has not considered how the data will be collected, and has not found a literature where her inquiry may contribute to addressing a wider question.

2. You are the resident director of a yearlong study abroad program in $\mathrm{La} \mathrm{Paz,} \mathrm{Bolivia.} \mathrm{A} \mathrm{student} \mathrm{enters} \mathrm{your} \mathrm{office} \mathrm{the} \mathrm{first} \mathrm{week} \mathrm{after} \mathrm{arrival}$ and requests your blessing to study Bolivian street children and how it feels to be an orphan. The student, a male in engineering, has earned average grades in his two years of college level Spanish, has taken an introductory psychology course as a freshman but never a research methods course, and will be living with a young, childless couple in an upscale section of La Paz. The student has come to you for direction on the project and wishes to begin immediately.

3. You are an assistant professor in your university's sociology department and also serve as the department's liaison with the campus study abroad office. Students majoring in sociology and contemplating study abroad must meet with you before studying abroad. A student comes to you seeking your endorsement for a proposed study of how sexually transmitted diseases were handled in ancient Rome. Your signature on her proposed study is required by the study abroad office to provisionally ensure that the student, a female, will earn major credit for the independent study. Upon further inquiry you learn that the student has not 
taken courses on ancient civilization and only has one year of collegelevel Italian. However, she has taken a research methods course as well as a course on human sexuality, and is also active in the campus gaylesbian-bisexual-transgender alliance.

4. Your institution or organization encourages students to undertake a research project while they are abroad. To facilitate this opportunity you are the main instructor of the research methods workshop that covers basic research methodology and ethics for pre-departure students. A student comes to you proposing to study, during a semester South Africa, women on HIV drugs without their husbands' knowledge. Already in a pre-med track, the student is passionate about the AIDS issue, has taken a research methods course, has established a relationship with a local hospital in South Africa where she will intern, and has drafted a list of interview questions.

The four scenarios sketched out above squarely meet our definition of undergraduate research abroad. Programs that encourage students to conduct observations and informal interviews with local people are certainly valuable, as are classes that require short research assignments. However, these activities do not constitute formal research and, therefore, do not require institutional review board oversight.

Where can study abroad advisors, resident directors, site directors, and faculty turn, when an outbound student wishes to study in dangerous circumstances, or plans to investigate an impossibly broad issue? At many institutions and sending organizations, there exists a body whose resources, consent-giving mechanisms, and research-training programs can provide proper guidance on the complexities that should be taken into account. In most cases, this is the Institutional Review Board (IRB).

\section{The Issue of Oversight}

We are not aware of an official accounting of how many institutions currently require official IRB oversight of undergraduate research, whether domestic research or abroad. However, the support for undergraduate research opportunities continues to grow. The Association of American Colleges and Universities (AAC\&U, 2007 and the 2007 National Survey of Student Engagement (NSSE, 2007) frank undergraduate research and study abroad among the most promising high-impact practices for undergraduates. Education abroad must also actively prepare for an increased demand for undergraduate research opportunities abroad. 
Institutions that currently have IRB requirements in place for undergraduates involved in research may not yet have extended these requirements to study abroad programs. A brief inquiry into the question of IRB oversight of undergraduate research finds that the majority of institutions still regard the watchful eye of a faculty member as sufficient. In this view, if the research is being undertaken as part of a class or a faculty member's own research that has already secured IRB approval, the standard of proper oversight has been satisfied. For example, students doing research on a School for Field Studies (SFS) program that includes human subjects will typically work on a project identified by SFS or collaborate with an SFS faculty member or center director under an approved research plan. Similarly, in Australia, where research by undergraduates is described as "low impact research" this type of inquiry is nearly always undertaken as part of a class group project for which the faculty member teaching the course has secured appropriate Human Ethics Committee clearance. A North American student enrolled in an Australian university class will participate as any other enrolled student in such a class.

Presently, only a small number of institutions, and even fewer study abroad programs, officially offer guidelines for undergraduate research. Northwestern University's Office for the Protection of Research Subjects (OPRS) website currently does not include any clear language specifically addressing undergraduate research requirements vis-à-vis the IRB, and its Policy Manual only briefly addresses student research as part of a course. (Yet Northwestern does encourage students to contact the director to inquire whether some form of formal review, even if expedited, based on a brief abstract of the proposed study, would be advisable. Other examples of institutions that currently post some statement about undergraduate research include, among others, the University of North Carolina, the University of Iowa, and the University of Illinois.

Within academic circles, IRB review is often regarded as onerous, cumbersome, and intrusive; in some disciplines it is regarded as neither appropriate nor helpful. In part this may be because IRBs have been heavily dominated by scientists to insure proper care of human subjects in research focused on medicine, pharmacy and other health care matters. For several reasons, IRB review of undergraduate research abroad is seen as being even less necessary. First, few faculty and administrators expect short-term undergraduate research projects to result in generalizable or original findings Further, there is a perception that few undergraduates have sufficient background to define an appropriate research project prior to the start of an overseas experience, thus leaving the issue of IRB approval to the study abroad program to resolve while the student 
is abroad. Although some universities and study abroad providers may encourage or include independent research as part of their general curriculum, few require that students first have their research plans approved by their home campus IRB or program IRB.

However, there are some exceptions. At Pacific Lutheran University, for example, every student research project that involves direct interaction with human subjects is reviewed. It is accepted that this is a significant undertaking, often with the review process taking several back-and-forth exchanges between the student and the board until the project is determined to be methodologically sound, feasible and ethical. Other circumstances on home campuses, however, may preclude undergraduate research from IRB considerations. Generally, research available to undergraduate students on the home campus comprises only a minor component of faculty directed research; in nearly all cases the faculty member has already secured their campus IRB approval and students themselves are not involved in the IRB process.

While increasing numbers of leading voices and organizations in the field of study abroad encourage student research overseas, there are still no widely available guidelines and structures to guide students to carry out their research abroad responsibly and successfully. According to the Forum on Education Abroad, "Independent research represents one of the highest achievements of undergraduate student learning. Completing serious, high-quality research requires critical thinking, analysis, and creativity." (http://www.forumea.org.) Given the importance that educators and practitioners in our field attach to undergraduates who wish to conduct research abroad, it is appropriate to consider what level of oversight should be made available for that research.

\section{Undergraduate Research Abroad}

This issue of Frontiers, the third in a series dedicated to undergraduate research abroad, highlights some of the best student research produced by Forum member institutions. Each student article submitted was reviewed blind by a panel of faculty readers, ranked, and selected for publication in this issue. The student achievement represented in this issue is uniformly exciting and praiseworthy.

The study abroad experience as a whole stands out from a student's traditional college experience by constituting a higher and more intense level of experiential learning. Simply flipping through a book and doing some internet research is insufficient to understand the host culture. Rather, by engaging local people, culture, and taking classes in local institutions in the host country, students gain the insight to begin extracting the essence of the 
host culture. As such, undergraduates who take on a research project while abroad find themselves in a position to have to think more even critically than if they were merely traveling overseas or engaging in coursework abroad. Study abroad research presents an ideal opportunity to learn about academic inquiry and to engage in the exhilarating search for answers in an independent, selfdriven way as nascent scholars. However, engaging in cultural discovery in the context of a structured research project, carries with it a range of risks and responsibilities to both students and their hosts. Education abroad professionals should give careful thought to these considerations. Students require the preparation that universities, study abroad offices, and programs can provide before they can carry out their research responsibly and ultimately in a way that will be satisfactory for all involved.

Within the field of education abroad, different programs have different goals and purposes. While some include a research component, others do not. Not all programs have the resources and personnel to adequately prepare and monitor student research abroad. Without this support, the research effort may be misguided or even damaging, thus defeating its very purpose. Furthermore, not all students are interested or motivated to conduct research abroad, which may lead to poor quality research or insufficient care for human subjects' protection. All of these potential limitations for undergraduate research during study abroad are understandable.

The focus of any given program determines the plausibility of a student research undertaking. For example, intensive language programs may be more difficult forums for carrying out research than discipline-specific programs that have structured research components already built in. An example of the latter would be programs run by the School for International Training (SIT), where all students participate in a Field Study Seminar that prepares them, with the help of SIT's internal IRB, to spend four to six weeks at the end of the semester collecting data for an Independent Study Project (ISP) paper.

Currently, only a relatively small number of programs make directed or independent research abroad possible. Of the 7,682 study abroad programs included in the 2007 IIEPassport Study Abroad Directory, only 1,884 have an "independent study" component and 1,474, have a "directed field study" component (personal communication, IIEPassport). Although these terms are not defined in the IIEPassport study, for the sake of our argument we understand independent and directed field study to ideally mean study abroad inquiry that is prepared with the help of faculty and/or the study abroad office prior to departure (hopefully involving some level of IRB-type oversight), is then 
monitored throughout the time abroad, and in the end is held accountable for a product, such as a presentation, paper or other project.

Research during study abroad may not be appropriate for every type of program and therefore should not be a blanket requirement of all students. For those students who seek an opportunity to expand their academic horizons through independent inquiry, research abroad can be highly rewarding and leave a lasting impression. This benefit should extend not only to students but also to their sending institutions, receiving programs, and members of the host community being studied. Rigorous and meaningful research can be produced when the research is properly prepared, carefully monitored, and appropriately supported, and in the end potentially meaningful and worth recognizing.

Who, then, is responsible for the risks and liabilities that students assume while they conduct research abroad? The sending institution; the study abroad program provider; a professor or academic advisor at the home institution; an on-site director or faculty member; the student her or himself; another party or individual; or no one at all? What should the level of oversight be and consist of? Full Institutional Review Board approval by the home institution or the program provider prior to departure; consent of a study abroad office or an academic advisor either at the home institution or receiving institution or program; general oversight by the resident director; something less; or nothing at all?

In the sections below we explore these questions by examining what undergraduate research during study abroad means and involves and the possible role an IRB can or should play, and how study abroad programs and advisors may approach helping students undertake research abroad.

\section{Undergraduate Research and Institutional Review B o a r ds}

Since 1974, oversight of university research has been the domain of campus Institutional Review Boards. The United States government defines IRB oversight in the following way:

The IRB is an administrative body established to protect the rights and welfare of human research subjects recruited to participate in research activities conducted under the auspices of the institution with which it is affiliated. The IRB has the authority to approve, require modifications in, or disapprove all research activities that fall within its jurisdiction as specified by both the federal regulations and local institutional policy. Research that has been reviewed and approved by an IRB may be subject to review and disapproval by officials of the 
institution. However, those officials may not approve research if it has been disapproved by the IRB. [Federal Policy $\left.\S \_.112\right]$.

(Institutional Review Board Guidebook, 1993)

Institutional Review Boards (also known as Human Subject Research Boards or Human Participant Research Boards) are the responsible bodies on American college campuses charged with establishing and implementing the policies and procedures that govern human participation in research projects. Ideally, risk to universities of non-compliance with federal procedures is reduced by the formal inclusion of IRB procedures in the personnel manual of a university, and especially in a faculty handbook. However, not all institutions that conduct research have IRBs, since they are only legally required if the research is federally funded. All institutions that receive federal funds for research with human subjects, whether faculty or students conduct it, must have a current Federalwide Assurance (FWA) on file with the Office of Human Research Protections in the U.S. Department of Health and Human Services. The FWA gives the OHRPs the right to oversee the university's compliance with the requirements on the funded project, or on all projects if the university applies for extended oversight. (http://www.hhs.gov/ohrp/humansubjects/guidance)

Even so, no accredited institution today would likely go on record arguing against the protection of human research subjects as a moral and professional obligation. Despite this, there has been much controversy over the extent to which IRB's should be allowed to investigate and, some feel, be permitted to prohibit research from being carried out. In the starkest critique, some even argue that IRBs encroach on free speech (Hamburger, 2005). The question has also arisen as to who, exactly, should be required to bring their research before an IRB. It may seem unduly onerous that undergraduates doing research during study abroad should be required to go before an IRB with their project prior to departure. Yet some students returning from study aboard with completed research projects have been denied the use of their collected data $f$ for lack of pre-approval.

While we can debate whether undergraduate research needs to meet the rigorous standard of originality generally expected of established scholars, we cannot ignore the fact that even beginner level research should strive to meet standard criteria of ethical inquiry, methodological clarity, and structural soundness.

When undergraduate research is independently conducted and occurs outside the controlled environment of a structured university course, as in study abroad, the question of oversight becomes critically important. When student research is 
taken out of the normal operation of a class and becomes a self-driven endeavor, some formal mechanism of oversight and pre-approval is necessary. This is particularly true if the student wishes to publish the research or otherwise publicly share or use the data in the name of their home or host institution, even if the realization of these possibilities comes only after a positive research experience.

\section{Inherent Risks and Opportunities in Study Abroad Research}

If institutions and programs offer their students the opportunity to systematize some aspect of study abroad learning through a structured independent research project - and more importantly if they require it - they also assume the responsibility to provide students with the training and tools they will need. This is obligatory for sending and hosting institutions and organizations, which jointly bear responsibility for the student's conduct, and even more importantly for the human subjects. Institutional review protects subjects from potential harm (e.g physical, psychological, financial, emotional), and also protects the students from potential harm. In addition, it forces students to write a research proposal, with a detailed plan for how, where, when and with whom they plan to conduct their research. IRB reviewers, are sensitive about protecting subjects, can assess the safety; the feasibility and the cultural appropriateness of the proposed research and help students revise their proposals as needed. As the examples at the beginning of this introduction illustrate, students are often naive about the kinds of research projects that are culturally appropriate and feasible.

The opportunity to conduct research while abroad has many potential benefits. Faculty mentors of such research maintain that having to think through a project and write a proposal as part of a review procedure nearly always results in a better project. This process forces students to generate a research question or hypothesis, choose a data collection method (interviews, focus groups, questionnaires, observations), create research instruments (questionnaires or interview or focus group protocols) and have a plan for analyzing the data they collect. For some students a research experience provides new direction and for others a new or renewed commitment to academics or career goals. Further, the experience may be an ideal catalyst for meaningful and ultimately rewarding research that for many students can result in honors theses, grants, fellowships, faculty and institutional recognition, graduate school essay material, conference papers, and even publishable first time papers. For undergraduates, understanding early on the professional parameters expected in academia (such as going through the IRB), promotes future professional and ethical research conduct. In one study, 
undergraduates who were required by their instructor to go through the IRB reported learning more, producing a stronger product, viewing their professor more positively, regarding their research more seriously, and becoming better versed on ethical issues (Kalgren \& Tauber, 1996). Should this be any different for undergraduate study abroad research?

\section{Suggestions for the Future}

Although we strongly advocate some level of IRB review for undergraduate research during study abroad, for some programs a complete, formal IRB review process may prove unduly stringent or burdensome. In this case, students should consider a project model that may not, in fact, require institutional review. Two models are appropriate in that case:

1. Participant observation research, whereby the student collects data in a natural, usually public, setting, e.g. schools, playgrounds, parks, churches, restaurants, buses, etc. Because the setting is public and the student has a legitimate role in the setting (a volunteer, a worshipper, a diner, a bus rider, this type of research does not typically require institutional review. This will vary by institution, but at many colleges and universities this type of research is often exempt from review. The student-observer may be overt (tell people s/he is conducting observational research) or covert. Data are collected through observation, conversation and participation. Participant observation research can be combined with service learning and internships, so it is a promising methodology for study abroad students.

2. Unobtrusive methods. This is a catchall term for social research that does not involve direct contact with humans, but rather with their products. Student researchers studying abroad can analyze local media (TV shows, ads, newspaper articles, obituaries, music lyrics), examine institutional records (e.g. court documents, national archives, government documents) or social artifacts (art, signs, architecture). Again, this type of research does not typically require institutional review. However, if a questionnaire is added to this type of research, IRB approval may become necessary.

The real challenge comes with those students who are considering independent research in a setting where they will be collecting data, possibly of a sensitive nature, largely unsupervised. This type of research invites many potential risks, but these can also be minimized with adequate guidance. Without it, students abroad may engage in projects that are poorly conceived, 
originate from a dichotomist or even false understanding of a culture, place the student in potential danger during the research, result in an unacceptable product, if completed at all, or place greater risk for liability on the home or sponsoring institution. Sending institutions or study abroad programs that incorporate a research component into their curricula face the challenge of guiding students away from inappropriate research.

Many proposed undergraduate research projects can be excellent and carried out with great success. However, it lies in the skills of the supervising university faculty or study abroad advisor to guide students from the early conception of a research idea, through the training in research theory and methodology, to the data collection, analysis, and writing. Given the considerable expertise and work involved, it is certainly legitimate to ask whether this training and oversight should even be the responsibility of study abroad advisors or whether this purview is better left with appropriate faculty. When programs are not able to make available to students appropriately skilled and knowledgeable faculty, some type of IRB oversight or assistance is important to consider carefully. Each of the following suggestions, from full IRB oversight to minimal guidance, provides at least some protection for the institution, the student, and the human subjects studied.

1. IRB review required of all students planning to conduct research abroad. This review may be expedited, but student research would still pass by some level of oversight by trained and certified IRB personnel. Faculty mentorship to prepare for IRB review would also help reduce the workload of the institutional review board and give the student help designing an appropriate research project. Further, additional work and responsibility then would not fall on study abroad staff, who may not have sufficient research training and background.

2. Individual program providers develop their own IRBs. An example of this is the School of International Training (SIT). An Independent Study Project is a cornerstone of each of SIT's programs, and students doing research on human subjects are required to comply with federal IRB standards. Their website states:

The policy is designed to help students develop and implement Independent Study Projects that are ethically grounded, culturally sensitive, and respectful of research participants. This process includes local 
review boards at program sites and an institutional review board based in Brattleboro. Both will be available to act on any ISP [Independent Study Project] student proposals that raise concerns or questions that cannot be resolved by the academic director and student together.

(http://www.sit.edu/studyabroad/advisors/research_isps.html.)

To facilitate this, SIT has established a local review board at each of its program sites, as well as an IRB in Brattleboro, VT where it is based. The later is registered with the Office of Human Research Protections in HHS. ( http://www.sit.edu/studyabroad/docs/human_subjects_policy. pdf. ) 1 SIT has done so in part because "informed consent" as understood in the US may be misunderstood or completely confounding in an overseas cultural context. For example, in some parts of Africa informed consent needs to be given by the elders of a village and may not be available from each individual who is part of the research. In other instances, a written informed consent approval form may need to be translated, signed by the participant with their thumbprint and witnessed by the translator who read them the consent document. Still, if a student on an SIT program plans to include human subjects in their ISP, they are strongly encouraged to begin the research process with their home institution's IRB so the research may be accepted there upon return. On some campuses, this level of home institution oversight may also be essential if the student plans to earn credit for the research.

3. Study abroad offices on campus create an undergraduate research program especially designed for outbound students planning to conduct research abroad. At Northwestern University, for example, the Study Abroad Office created a Study Abroad Research Program (SARP) that invites outbound students to attend a series of seven workshops that cover issues related to research abroad and require students in the end to write a research proposal aligned with IRB standards and regulations for their study abroad. The Study Abroad Research Program (SARP) is a course that students preparing to go abroad take the semester before departure. The class is made up of seven workshops which cover, among other things, how to develop a research question, research methods, research ethics, using electronic resources, and writing a research proposal. The range of research topics covered by students in the SARP program has been wide, including studies of urbanization in Egypt, Sufi music in Morocco, school reform 
in South Africa, Jewish communities in Bolivia, same sex marriage in France, and gender ideology in Greece, among many others.

4. Direct faculty-student mentoring.

i. Research that is essentially initiated by a faculty member or by the faculty and student together. In this form, the faculty member takes primary responsibility for the review process but the student helps by collecting data while studying abroad. This situation gives the student an opportunity not only to work with a faculty member who is specifically specialized in their field of interest for their research project, but also allows him or her to gain from the direct insight of someone who has had to go through the IRB processes themselves. Students working with faculty, thus, not only fall under faculty IRB clearance when they work with faculty on a project, but they also gain the tutelage of the mentoring faculty member if they must secure IRB clearance for their independent project later.

ii. Research that is initiated by the student, perhaps for an honors or capstone project. In this form the student takes primary responsibility for conceptualizing the project, initiating institutional review, and collecting the data, but all with on-going oversight and help from a faculty member.

5. A workshop on IRB and buman subject protection standards, followed by a contract students sign pledging to observe ethical standards. Although such a workshop is not equivalent to nor a sufficient replacement for full IRB review, exposing students on campus to research methods and ethics questions will likely serve to raise consciousness on the issues.

6. A required agreement that all outbound students must sign, thus protecting the university from liability. This contract would state that a student

i. will not conduct research on human subjects without appropriate institutional review, and

ii. will not harm human subjects (with "harm" explicitly defined by the institution's IRB).

However, for a student working without a faculty mentor or without an accompanying training workshop, such an agreement does little to help the student and, in fact, may only minimally protect the institution. 


\section{Conclusion}

At a minimum, it is important that the field of education abroad carefully consider all of the myriad responsibilities, risks, and opportunities related to undergraduate research during study abroad. Education abroad professionals who actively work with undergraduates who plan to conduct research abroad should insure that some degree of IRB standards, or at least IRB-influenced standards, are considered in the development of any program that supports undergraduate research abroad. This would be wise not only for the safety of research subjects and beneficial to the students involved, but also important for liability issues the home institution or program provider may otherwise face. Not implementing IRB standards for undergraduate research abroad may lead to the untenable situation in which an institution, or even the field as a whole, finds itself challenged for what it should have known earlier and acted upon differently.

\section{A ck now l edge me n t s}

Bernhard would like to give special recognition to Matthew Nusko for his invaluable help in researching and structuring this article. Neal offers special thanks to AustraLearn for whom he undertook a review of Australian university policies and human subject research, Dr. David Shallenberger of SIT for ongoing conversation about study abroad and undergraduate research, and Dr. Kay McDade for her helpful comments on an earlier draft of this article.

\section{B i b l i o g r a p h y}

The Boyer Commission on Educating Undergraduates in the Research University.

Reinventing Undergraduate Education: A Blueprint for America's Research Universities. 1998: State University of New York, Stony Brook, NY. <http:// naples.cc.sunysb.edu/Pres/boyer.nsf/webform/contents $>$.

College Learning for the New Global Century. 2007: Association of American Colleges and Universities. Washington, DC.

Council on Undergraduate Research, http://www.cur.org/about.html. Retrieved June 14, 2007.Experiences that Matter: Enhancing Student Learning and Success. 2007: National Survey of Student Engagement (NSSE), Annual Report Bloomington, IN.

Department of Health and Human Services http://www.hhs.gov/ohrp/ humansubjects/guidance/45cfr46.htm. Retrieved July 15, 2007.

Forum on Education Abroad http://www.forumea.org. Retrieved May 23, 2007

Fortenberry, Normal L. "Integration of Research and Curriculum." Council on Undergraduate Research Quarterly. (1998): 54-61 
Forum on Education Abroad. 23 May 2007 <http://www.forumea.org/>

Gonzalez, Cristina. "Undergraduate Research, Graduate Mentoring, and the University's Mission.” Science. 293 (2001): 1624-1626.

Hamburger, Philip. "The New Censorship: Institutional Review Boards." (May 2005). University of Chicago, Public Law Working Paper No. 95.

Institutional Review Board Guidebook. Chapter I. Retrieved August 18, 2007. http://www.hhs.gov/ohrp/irb/irb_chapter1.htm.

Kallgren, Carl A. and Robert T. Tauber. "Undergraduate Research and the Institutional Review Board: A Mismatch or Happy Marriage?.” Teaching of Psychology. 23.1 (1996): 20-25.

Katkin, Wendy. "The Boyer Commission Report and Its Impact on Undergraduate Research." New Directions for Teaching and Learning. 93 (2003): 19-38.

Lopatto, David. "Survey of Undergraduate Research Experiences (SURE): First Findings." Cell Biology Education. 3 (2004): 270-277.

Northwestern University www.research.northwestern.edu/research/OPRS/irb/ School for Field Studies http:// fieldstudies.org/pages/67_research_opportunities_ with_sfs.cfm. Retrieved August 12, 2007.

School for International Training : http://www.sit.edu/studyabroad/advisors/ research_isps.html. Retrieved June 15, 2007.

School for International Training http://www.sit.edu/studyabroad/docs/ human_subjects_policy.pdf. Retrieved July 15, 2007

University of Illinois, Chicago http://tigger.uic.edu/depts/ovcr/research/protocolreview/irb/index.shtml

University of Iowa http://research.uiowa.edu/hso/index.php?get=inv_guide_ toc; University of North Carolina http://ohre.unc.edu/sop/IRB_SOPs 12-12-03 final.pdf;

\section{Further Resources}

Bowman, Kirk S., and Ashley Jennings. "Pura Vida: Using Study Abroad to Engage Undergraduate Students in Comparative Politics Research." PS: Political Science and Politics. 38 (2005): 77-81

Ceci, Stephen J., Douglas Peters, and Jonathan Plotkin. "Human Subjects Review, Personal Values, and the Regulation of Social Science Research." American Psychologist. 40.9 (1985): 994-1002.

Christakis, Nicholas A. "Should IRBs Monitor Research More Strictly?" IRB: Ethics and Human Research. 10.2 (1988): 8-10.

Cohen, Patricia. "As Ethics Panels Expand Grip, No Research Field Is Off Limits." The New York Times. 28 Feb. 2007: A1, A15. 
Grunig, Stephen D. "Research Reputation, and Resources: The Effect of Research Activity on Perceptions of Undergraduate Education and Institutional Resource Acquisition." Journal of Higher Education. 68.1 (1997): 17-52.

Hemmings, Annette. "Great Ethical Divides: Bridging the Gap Between

Institutional Review Boards and Researchers." Educational Researcher. 35.4 (2006): 12-18.

Hopkins, J. Roy. "Studying Abroad As a Form of Experiential Education." Liberal Education. 85. 3 (1999).

Howe, Kenneth R. "Ethics, Institutional Review Boards, and the Changing Face of Educational Research." Educational Researcher. 22.9 (1993): 1621.

Hughes, Teresa A., William Allan Kritsonis, David E. Herrington, Mary Alice Kristonis. "A National Perspective for Cultivating Working Relationships Between Educational Researchers and Institutional Review Board Members." The Lamar University Electronic Journal of Student Research. 3 (2006): $1-5$.

Hutchings, Pat. "Competing Goods: Ethical Issues in the Scholarship of Teaching and Learning." Change. September/October (2003): 27-33.

IIEPassport Academic Year Abroad, 2007-2008 (36th edition). New York: Institute of International Education. http://IIEPassport.org

Penslar, Robin Levin, and Joan P. Porter. Institutional Review Board Guidebook. 1993: Office for Human Research Protections. <http://www. hhs.gov/ohrp/irb/irb_guidebook.htm >

Robertson, Jan. "The Three Rs of Action Research Methodology: reciprocity, reflexivity and reflection-on-reality." Educational Action Research. 8.2 (2000): 307-326.

Rosenstiel, Stephen F., and William M. Johnston. "Goals, Costs, and Outcomes of a Predoctoral Student Research Program." Journal of Dental Education. 66.12 (2002): 1368-1373. 